\title{
Knowledge and Practice of Iraqi Women Regarding Breast Self- Examination
}

\author{
Taqi Mohammed Jwad Taher ${ }^{1 *}$ \\ ${ }^{1}$ Department of Family and Community Medicine, College of Medicine, Wasit University, Wasit, Iraq \\ * Corresponding author: Taqi Mohammed Jwad Taher E-mail: ttahir@uowasit.edu.iq ORCID: 0000-0002-0954-5440 \\ Received: 12 July 2021 Accepted: 5 October 2021
}

\begin{abstract}
Background: Women around the world are suffering from breast cancer (BC) which is considering the commonest cancer affecting them. Even, the mortality rate can be decreased with a continuous and regular screening of the breast especially by Breast Self-Examination (BSE).
\end{abstract}

Objectives: The main objective of this study was to assess the knowledge level, attitude level, and practice of Iraqi women living in Baghdad city regarding BSE. Secondly, to assess the presence of an association between knowledge and practice.

Methods: This is an analytic cross-sectional study conducted on a non-random sample of 657 participant women attending primary healthcare centers (PHCCs) for different reasons. The average age was between (20-59) years. All consented women filled a specially designed questionnaire for the research purpose through a face-to-face interview.

Results: The result showed only $75.5 \%$ of women were heard about BSE and there was a significant difference $(p<0.001)$ in age between women heard about BSE and those never heard it. In addition to the significant association $(p<0.001)$, $(p<0.001)$, and $(p<0.001)$ of being aware of BSE with educational level, employment status, and social class respectively. The mean knowledge score and standard deviation (SD) for BSE were (45.2 \pm 34.8$)$. Only 33(5\%) of women performed regular monthly BSE. A significant difference $(P<0.001)$ in the knowledge of women who practicing BSE adequately and those with non-adequate practice.

Conclusion: Women with the adequate practice of BSE had a higher knowledge level than those inadequately practiced. The practice of BSE was inadequate in a majority of participants and needs to be improved by educational programs.

Keywords: knowledge, attitude, practice, breast self-examination, breast cancer

\section{INTRODUCTION}

Among all malignant diseases, breast cancer is the type of malignant tumor that mostly affects women in higher percentages. It was found that 2.1 million females having this cancer each year. In addition to the highest death rate from cancer among women around the world which was estimated by the World Health Organization (WHO) report in 2018 to be equal to $15 \%$ of all cancer death [1-8]. Although the newly reported cases seem to be higher in developed countries, the mortality rate from it still appears to be higher 
in developing countries. This difference in the risk and incidence rate was attributed to many factors such as reproductive and lifestyle factors in addition to lower screening rates and inefficient reporting of cases in developing regions $[9,10]$.

The total deaths from breast cancer among both males and females were found to be more than 600,000 deaths during 2018. So, it was considered as the first cause of death from cancer among females and second among both genders $[10,11]$.

In Iraq, the Ministry of Health $(\mathrm{MOH})$ reported breast cancer the first among other cancers during 2012. The total cases were 4115 and only 91 of them were in males [12]. So, being the commonest cancer in Iraq and the increasing of the incidence rate along the years in addition to effecting even younger age women gave the opportunities to focus on early diagnosis and treatment because previous studies found that it can improve the curing and decrease the mortality rate more than $95 \%[13,14]$. The easiest and cheapest screening way for identification of breast cancer is the Breast self-examination (BSE) which can identify more than $90 \%$ of breast tumors at an early stage and by women themselves $[2,15,16]$. Therefore, women need to be knowledgeable of the proper ways for early detection of breast cancer $(\mathrm{BC})$ as a lot of studies previously mentioned that good knowledge and attitudes can positively affect practice behaviors [4]. Thus, this research was conducted to assess the knowledge, attitude, and practice regarding BSE among a sample of Iraqi women. Besides, the assessment of any present association between knowledge practice.

It will be of great benefit to healthcare professionals and decision-makers to focus on the educational programs that targeting women to being responsible for their breast health for early detection and treatment of $\mathrm{BC}$ before being complicated and difficult to manage with.

\section{MATERIALS AND METHOD}

\section{Study Design and Setting}

This is an observational analytic cross-sectional study in six Primary Health Care Centers (PHCCs) selected from all health sector centers in the Baghdad city. All of them were providing Maternal and Child Health $(\mathrm{MCH})$ services.

\section{Sampling and Sample Size}

The final calculated sample size according to the equation related to the cross-sectional study was 687 . A convenient non- random sample was selected from women attending PHCCs in Baghdad city for various reasons.

\section{Inclusion Criteria}

All women attending the selected centers during the period of data collection aged 20-60 years old.

\section{Exclusion Criteria}

Women visiting PHCCs for breast problems, those who previously diagnosed or with a family history of breast cancer, and those with acute conditions.

\section{Time of the Study}

The study was conducted in 2018 and data collection was carried during March and April 2018.

\section{Data Collection Tools}

Data from participants was collected through face-to-face interview by using a structured questionnaire form that designed for the present study and derived from a previous study in Botswana [17], the questionnaire was modified to be suitable to the Iraqi community, translated from English to Arabic, tested for validity by two expert professionals and tested for reliability by a pilot study on 5 women who were excluded later from the study results.

Sociodemographic features of participant women were collected by the questionnaire. Knowledge of breast selfexamination was assessed by 7 questions related (starting age of practicing BSE, frequency, appropriate timing, and the proper way of BSE practice), the attitude was assessed by 3 items, while practice was either being adequate or not according to the American Cancer Society guidelines (optional monthly BSE for women above 20 years of age) for average-risk and asymptomatic women [18].

\section{Knowledge and Attitude Score}

Each correctly answered knowledge question has received a score of one. The scores on knowledge items were summed and then multiplied by 100 divided by the total count of items to yield a knowledge score with a maximum of 100 .

For attitude, each item was answered by one of the Likert scales 5 grades from 1 which represented (strongly disagree) to 5 which represented (strongly agree). The attitude scores were weighted to a maximum of 100 (to simplify comprehension of score magnitude). The formula for this procedure is the multiplication of the resulting score by $100 /$ (the total number of attitude items $\times 5$ ).

\section{Statistical Analysis}

Data collected from women by the questionnaire were entered into the software program SPSS version 26 to be 


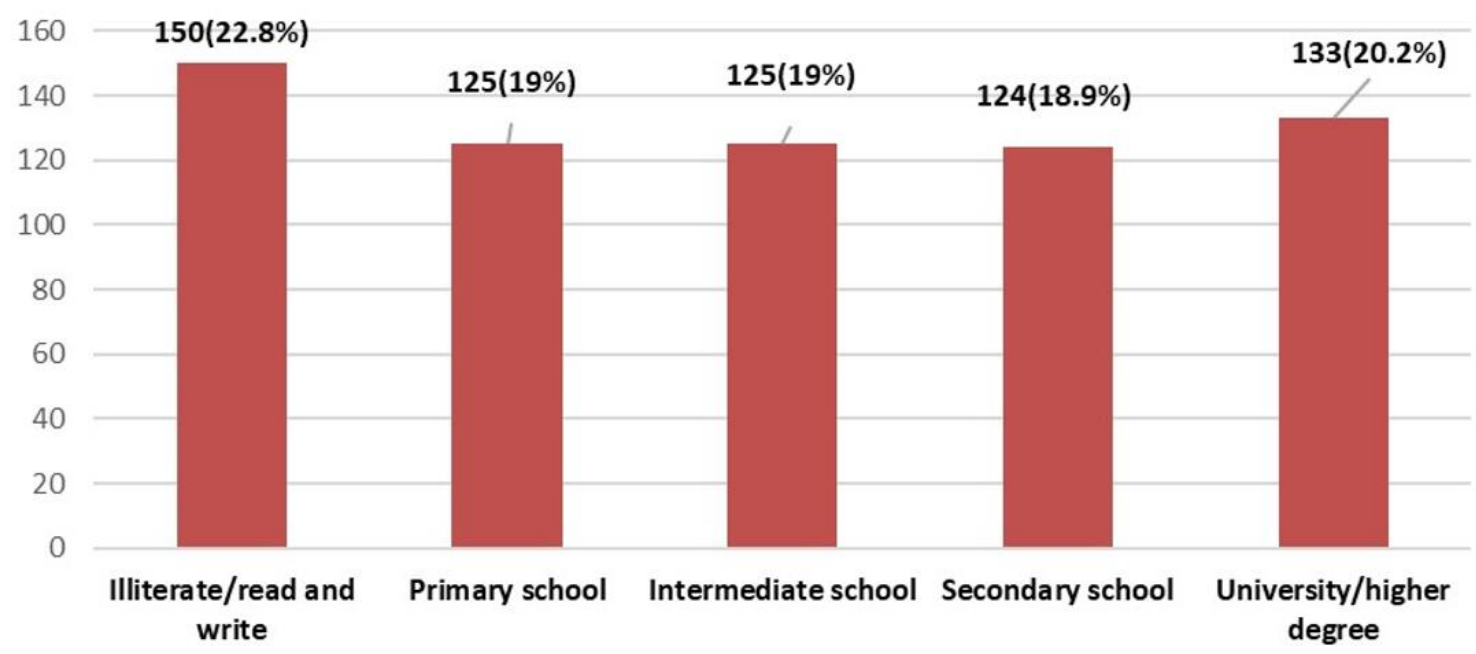

Figure 1. Educational levels of the respondent women

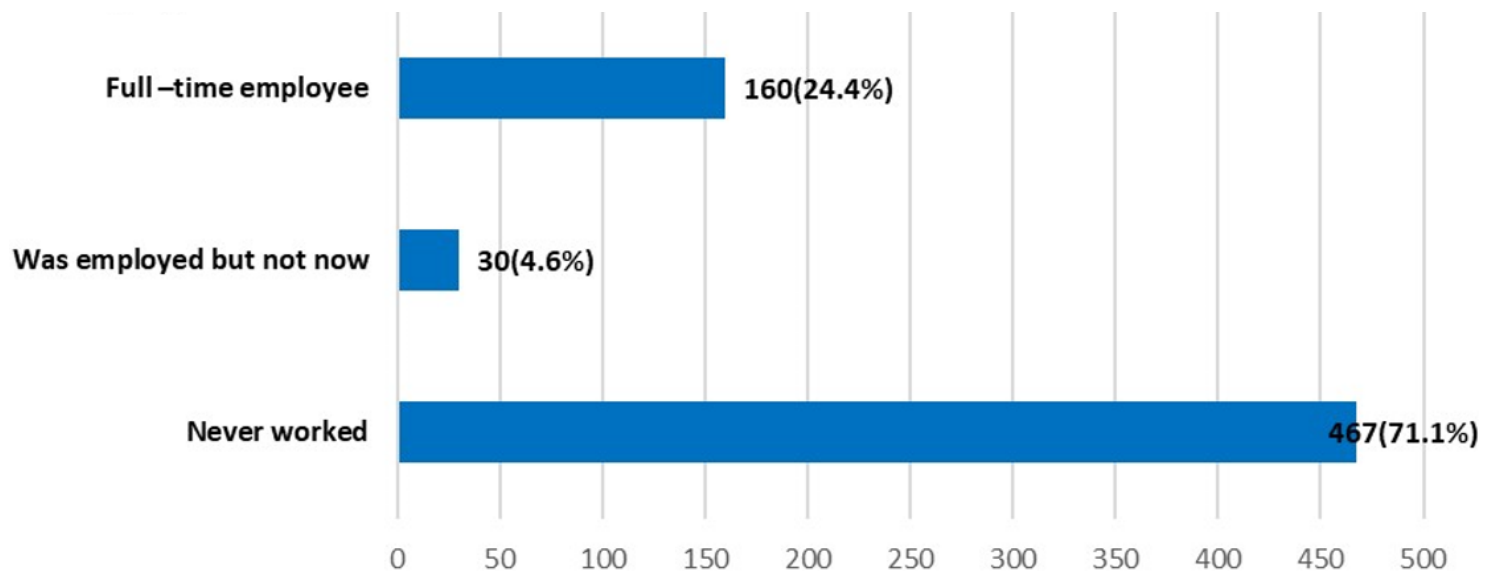

Figure 2. Frequency distribution of the employment status of the participant women

analyzed. Categorial variables were simply presented as frequency and percentages, while the quantitative variables were presented by the means and standard deviations (SD). The statistical test used to assess associations was the chisquare test. For the difference in mean between quantitative variables, the researcher used the independent samples ttest under the assumption of normal distribution between 2 groups. Association was considered as statistically significant if a P-value is less than 0.05 .

\section{Ethical Issues}

Official approvals from College of Medicine in Wasit University were obtained before the study. All participant women were told that their data will keep confidential and they informed about the aim of the study and were signed a consent form to participate in the study.

\section{RESULTS}

These study results were based on the analysis of 657 women who only accepted to participate from 687 eligible

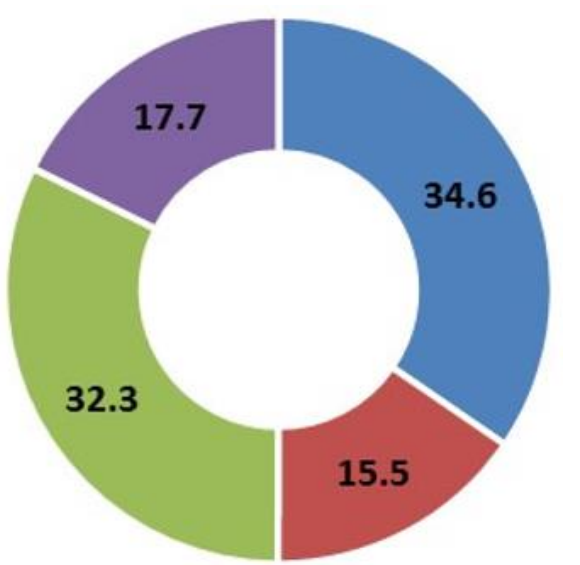

\section{- High social class \\ - Middle low class \\ - Middle high class \\ - Low social class}

Figure 3. Frequency distribution of social class percentages among participant women

women. Their ages ranging between 20 and 59 years old and a mean of (37.6 \pm 11.3$)$ years.

According to Figures 1-3, near one quarter (22.8\%) of the respondents were illiterate and with no education. The majority of the respondents $(71.1 \%)$ were housewives. The 
Taher / Women's Knowledge About Breast-Self Examination

Table 1. Distribution of participant women who ever heard of BSE according to socio-demographic variables

\begin{tabular}{|c|c|c|c|c|c|c|c|}
\hline \multirow{3}{*}{$\begin{array}{c}\text { Socio-demographic variables } \\
\text { Age in years: mean (SD) }\end{array}$} & \multicolumn{4}{|c|}{ Ever heard about breast self-exam. } & \multirow{2}{*}{\multicolumn{2}{|c|}{ Total }} & \multirow{3}{*}{$\begin{array}{c}P \text {-value } \\
<0.001 \\
\text { (t-test) }\end{array}$} \\
\hline & \multicolumn{2}{|c|}{ No } & \multicolumn{2}{|c|}{ Yes } & & & \\
\hline & 40.4 & $(13.3)$ & 36.6 & $(10.4)$ & 37.5 & $(11.3)$ & \\
\hline & No. & (\%) & No. & (\%) & No. & (\%) & \\
\hline \multicolumn{7}{|l|}{ Education } & \multirow{6}{*}{$\begin{array}{c}<0.001 \\
\text { (Chi-square) }\end{array}$} \\
\hline No formal education & 104 & (69.3) & 46 & $(30.7)$ & 150 & $(100.0)$ & \\
\hline Primary school & 1 & $(0.8)$ & 124 & $(99.2)$ & 125 & $(100.0)$ & \\
\hline Intermediate school & 40 & $(32)$ & 85 & $(68.0)$ & 125 & $(100.0)$ & \\
\hline Secondary school & 2 & $(1.6)$ & 122 & (98.4) & 124 & $(100.0)$ & \\
\hline University/higher degree & 14 & $(10.5)$ & 119 & $(89.5)$ & 133 & $(100.0)$ & \\
\hline \multicolumn{7}{|l|}{ Employment status } & \multirow{4}{*}{$\begin{array}{c}<0.001 \\
\text { (Chi-square) }\end{array}$} \\
\hline Never worked & 135 & $(28.9)$ & 332 & $(71.1)$ & 467 & $(100.0)$ & \\
\hline Previously employed & 12 & $(40)$ & 18 & $(60.0)$ & 30 & $(100.0)$ & \\
\hline Full-time employee & 14 & $(8.8)$ & 146 & $(91.3)$ & 160 & $(100.0)$ & \\
\hline \multicolumn{7}{|l|}{ Social classes } & \multirow{5}{*}{$\begin{array}{c}<0.001 \\
\text { (Chi-square) }\end{array}$} \\
\hline High social class & 54 & $(23.8)$ & 173 & $(76.2)$ & 227 & $(100.0)$ & \\
\hline Middle high class & 0 & $(0)$ & 102 & $(100.0)$ & 102 & $(100.0)$ & \\
\hline Middle low class & 71 & $(33.5)$ & 141 & $(66.5)$ & 212 & $(100.0)$ & \\
\hline Low social class & 36 & $(31)$ & 80 & $(69.0)$ & 116 & $(100.0)$ & \\
\hline Total & 161 & $(24.5)$ & 496 & $(75.5)$ & 657 & $(100.0)$ & \\
\hline
\end{tabular}

Table 2. Frequency distribution of positive knowledge items for BSE among 496 women ever heard of BSE

\begin{tabular}{|c|c|c|}
\hline Knowledge items for breast self-examination & No. & $\%$ \\
\hline BSE is a recommended practice from an early age ( 20 years and above) & 353 & 71.2 \\
\hline BSE should be routinely done at least monthly & 273 & 55.0 \\
\hline It is recommended to perform BSE about 7-10 days after the first day of menstruation & 162 & 32.7 \\
\hline Using a mirror to visualize breast is of great importance for the examination & 448 & 90.3 \\
\hline When examining the breast, you should squeeze the nipple and feel under the armpit & 413 & 83.3 \\
\hline Squeezing the nipple is necessary for a good examination & 305 & 61.5 \\
\hline Using fingers palm for detecting a breast lump & 123 & 24.8 \\
\hline
\end{tabular}

Table 3. Frequency distribution of positive attitude items for BSE among 496 women ever heard of BSE

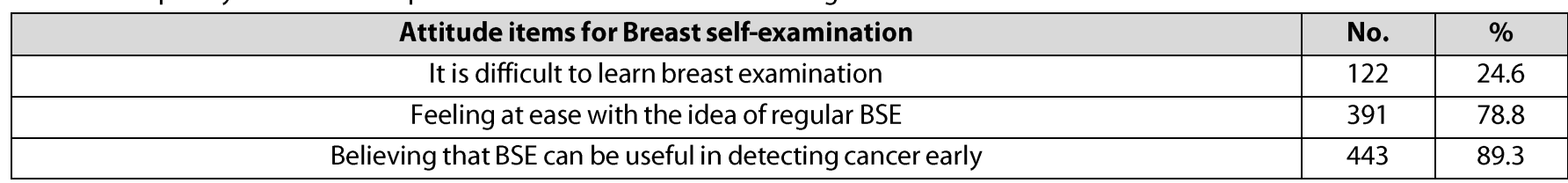

highest percentage $(47.8 \%)$ of women laid in the middle social class, followed by (34.6\%) in high class.

Around three quarters 496 (75.5\%) of them ever heard of BSE. Table 1 shows a significant association was found between selected socio-demographic variables with ever heard of BSE.

In Table 2, only one-quarter (24.8\%) of women heard of BSE knew that the fingers palms are used to detect a lump. $90.3 \%$ knew the importance of visualized breast by using the mirror is an important part of BSE.
Table 3 showed some attitude items related to BSE. The majority ( $89.3 \%$ ) believed that BSE can be useful in detecting cancer early. Only one quarter (24.6\%) thought of difficulty to examine their breasts.

For the current study, mean knowledge and attitude scores and standard deviations for BSE were 45.2 (34.8) and 76.7 (21.3) in respective order.

Only 33(5\%) of respondent women had adequate monthly practice according to the American Cancer Society recommendations (Table 4). 
Table 4. Frequency distribution of BSE practice among 657 women attending 6 PHCCs in Baghdad

\begin{tabular}{|c|c|c|c|}
\hline \multicolumn{2}{|c|}{ Frequency of performing breast self-examination } & No. & \% \\
\hline \multirow{3}{*}{ Not adequate practice } & Never practice & 498 & 75.8 \\
\cline { 2 - 4 } & Less than once a year & 30 & 4.6 \\
\cline { 2 - 5 } & Yearly & 23 & 3.5 \\
\cline { 2 - 5 } & Every 6 months & 73 & 11.1 \\
\hline Adequate practice & Monthly & 33 & 5.0 \\
\hline
\end{tabular}

Table 5. Comparison of the knowledge score of BSE between those adequately and not adequately practiced it among 657 women attending 6 PHCCs in Baghdad

\begin{tabular}{|c|c|c|c|}
\hline \multirow{2}{*}{ Knowledge score for BSE* } & Not adequate & Adequate** $^{*}$ & P-value \\
& $(t-t e s t)$ & $<0.001$ \\
\hline Range & $(0-100)$ & $(71.4-100)$ & \\
\hline Mean & 43.1 & 84.8 & \\
\hline SD & 34.4 & 6.1 & \\
\hline $\mathrm{n}$ & 624 & 33 & \\
\hline
\end{tabular}

*Breast Self-Examination

**Monthly examination.

In Table 5, it is obvious that the mean knowledge score of BSE for women adequately practiced BSE was significantly higher than for those who did not.

\section{DISCUSSION}

Although breast cancer is one of the most common cancers in women, most women do not know and have never heard about breast self-examination, which is considered one of the early detection methods for breast cancer in women and there was a knowledge deficit about it. Women need to understand the proper way, time, starting age, and frequency of BSE, so that to practice properly. More than half of women in this study knew that BSE should be routinely done at least monthly, only one quarter knew that $A$ quarter of women know that using the palm of the fingers for a breast examination is the best way to examine to detect any mass or lump in the breast. Therefore, it is necessary to teach women the correct way to examine by professionals. However, skills of practicing BSE were not established or examined in this study, which is considered a limitation of this study.

The insufficient knowledge of women regarding BSE in the current study was concurring with similar Iraqi researches conducted in an educated population [6], and in college students in Erbil city [19]. Other studies conducted in Saudi [20], Malaysia [21], India [22], and Iran [2] all showed similar results concerning the knowledge of BSE.

Previous studies confirmed that the regular and continuous practice of examination leads to a significant impact on treatment and disease progression, in addition to the chance of survival $[23,24]$. Despite this, only a small percentage of women have breast self-exams during their lifetime. Only $5 \%$ of them did it regularly each month. Similarly, another study conducted in Jordan reported that only one-quarter of the sample practiced BSE, $7 \%$ of them regularly practiced it [25]. Even in southeastern Iran, only 4.5 $\%$ of study participants practiced BSE monthly [2].

In contrast, a study conducted in Iraqi universities found that $48.3 \%$ of women in the educated population practiced BSE periodically [6]. More than half of urban Malaysian women practiced BSE, 28.1\% of them practiced monthly [26]. Another Malaysian study showed around a quarter of women practiced BSE monthly [27]. Other studies were done in Iraq [28], Saudi Arabia [29], and Iran [30]; even indicated a low rate of adequate BSE practice, but still higher than mentioned in the current study.

Even the majority of women in this study believed in the usefulness of BSE in early detection of breast cancer, near a quarter of the sample believed that it is difficult for women to examine her breasts and this may have a role in the low percentage of regular BSE practice among participant women. This low practice can also be explained by that they are not convinced are vulnerable to have breast cancer. Another most important cause of this low practice is the lack of sufficient education and knowledge about the benefit of early detection. So, it is of great importance to involve women in such training programs for the best knowledge and thus improving required practice.

Besides, women with adequate BSE practice had better knowledge of it. This gave the idea that increasing 
knowledge of BSE may lead to an increase in adequate practice, with more intention paid to more educational awareness. The same was proved by other studies performed in people in Western Turkey [31] and Malaysian female teachers [21] and the same association was also confirmed in Iranian [32] and female dental students in India [22].

In contrast to this finding, another study conducted for Malaysian female university students found a negative association between knowledge and BSE practice [33].

These results highlight that awareness and education programs can transform negative practices into positive ones. As shown in a study conducted in Iraq to find out the effect of educational programs regarding self-examination to increase women's knowledge about it, it concluded that these programs are of a significant impact on their knowledge to manage BSE [34]. Even, an Egyptian study found that $100 \%$ of women who never practice BSE mentioned not knowing how to do it. So, they were engaged in a learning course and became more aware of any abnormal changes in their breasts for early detection and treatment [35].

Studies conducted in developed countries found a higher rate of monthly BSE $[36,37]$ which might be contributed to improving education and awareness programs.

The findings in this study may underline the importance of educating women to routinely examine their breasts by related educational programs adopted by the policymakers and managers.

There were some limitations in our research. Firstly, the results were based on the responses the participant women visiting PHCCs who may already be in contact with the national program of breast cancer. The results obtained from them will very likely overestimate more desirable results. This bias limits the generalizability of results to all the women. However, knowing the situation under the best possible scenario is important in itself, as it may be used as an indicator of the level of the reproductive health educational role which should be expected to be disseminated through PHCCs.

The second limitation is the self-report subjective measure used which make some bias to appear in the result besides, recall bias. Lastly, Skills of practicing BSE were not mentioned in the current study.

However, the results give a hint about the low knowledge, attitude, and practice of Iraqi women concerning BSE.

\section{CONCLUSIONS AND RECOMMENDATIONS}

The majority of women in this study were of low knowledge scores regarding BSE. Besides, the majority were with inadequate practices regarding this procedure. This low level of practice was highly associated with knowledge. So, it is of great benefit for women to highlight the importance of screening by increasing awareness in addition to decrease barriers.

Women need to be educated about the most helpful, cheap, accessible, and easy way for early detection and screening for breast cancer. This education might overcome the confidence and fear problems from examining in the false time and way. Finally lead to early detection, management, and decrease deaths from breast cancer.

The demonstration of a positive association between knowledge and practice have risen the role of health planner to concentrate on the educational programs for targeting women.

Based on the low level of practice of BSE, strong support should be provided by the physician in motivating women to practice breast self-examination and concentration on the proper time, frequency, and the method of practicing should take the priority as most of the women not well knowledgeable about the proper way to examine their breast. This study recommends future studies performed on a larger sample from different places in Iraq. Need to study the barriers and motivations for BSE practice.

Funding: Author received no financial support for the research and/or authorship of this article.

Acknowledgements: Author acknowledges all women who have participated in the study.

Declaration of interest: Author declares no competing interest.

Data availability: Data generated or analysed during this study are available from the author on request.

\section{REFERENCES}

1. Dellie ST, Neguse TM, Demissie M, Rao D. Knowledge about breast cancer, risk factors, breast screening method and practice of breast screening among female healthcare professionals working in governmental hospitals, Addis Ababa, Ethiopia. J Pharm Biol Sci. 2012; 2 (1): 05-12. (doi: 10.9790/3008-0210512).

2. Heidari Z, Mahmoudzadeh-Sagheb H, Sakhavar N. Breast cancer screening knowledge and practice among women in southeast of Iran. Acta Medica Iranica. 2008; 46(4): 321-28. 
3. Habib F, Salman S, Safwat M, Shalaby S. Awareness and knowledge of breast cancer among university students in Al Madina Al Munawara Region. Middle East J Cancer. 2010; 1(4): 159-66.

4. Ahmed AM, Farghaly S, Darwish E. Knowledge, attitude, and practice of breast cancer screening among women visiting primary health care centers in Dubai. Egypt $J$ Community Med. 2010; 28(4): 21-38.

5. Tavafian SS, Hasani L, Aghamolaei T, Zare S, Gregory D. Prediction of breast self examination in a sample of Iranian women: An application of the health belief model. BMC Womens Health. 2009; 9: 37-43. (doi: 10.1186/1472-6874-9-37).

6. Alwan N, Al-Attar W, Eliessa R, Madfaie Z, Tawfeeq F. Knowledge, attitude and practice regarding breast cancer and breast self examination among a sample of the educated population in Iraq. EMHJ. 2012; 18 (4): 337 45. (doi: 10.26719/2012.18.4.337).

7. Gilani SI, Khurram M, Mazhar T, Mir ST, et al. Knowledge, attitude and practice of a Pakistani female cohort towards breast cancer. J Pak Med Assoc. 2010; 60(3): 2058.

8. WHO. Breast cancer. Available at: https://www.who.int/cancer/prevention/diagnosisscreening/breast-cancer/en/

9. American Cancer Society. Breast cancer facts and figures 2019-2020. Atlanta, GA: American Cancer Society, 2019.

10. Howlader N, Noone AM, Krapcho M, et al. SEER*Explorer. Recent trends in SEER mortality rates, 2000-2017, by race/ethnicity, male, all ages, all stages, observed rates. National Cancer Institute. 2020. Available at: https://seer.cancer.gov/explorer/ (Accessed: April 29, 2020).

11. Howlader N, Noone AM, Krapcho M, et al. Cancer statistics review, 1975-2017. National Cancer Institute. 2020. Available at: https://seer.cancer.gov/csr/ 1975_2017/ (Accessed: April 27, 2020).

12. Iraqi Cancer Registry 2012. Iraqi Cancer Board, Ministry of Health, Republic of Iraq, 2014. Available at: http://bccru.u obaghdad.edu.iq/wp-content/uploads/sites/41/uploads /My\%20Files/PDF/2012Iraqi\%20cancer_Arabic.pdf

13. Alwan N. Breast cancer: Demographic characteristics and clinico-pathological presentation of patients in Iraq. EMHJ. 2010; 16 (11): 1159-64. (doi: 10.26719/2010.16.11.1159).
14. WHO. Cancer Fact sheet $\mathrm{N}^{\circ} 297$. WHO 2012. Available at: http://www.emro.who.int/puplication

15. Bener A, Ayoubi HR, Moore MA, Basha B, Joseph S, Chouchane $L$. Do we need to maximize the breast cancer screening awareness? Experience with an endogamous society with high fertility. Asian Pac J Cancer Prev. 2009; 10(4):599-604.

16. Bassey RB, Irurhe NK, Olowoyeye A, Adeyomoye AA, Onajole AT. Knowledge, attitude and practice of breast self examination among nursing students in Lagos University Teaching Hospital, Nigeria. Educational Research J. 2011;2(6): 1232-6.

17. Tieng' OJG, Pengpid S, Skaal L, Peltzer K. Knowledge, attitude and practice of breast cancer examination among women attending a health facility in Gaborone, Botswana. Gend Behav. 2011; 9 (1): 3513-27. (doi: 10.4314/gab.v9i1.67455).

18. Smith RA, Cokkinides V, Eyre HJ. American Cancer Society guidelines for the early detection of cancer. CA Cancer J Clin. 2005; 55(1): 31-44. (doi: 10.3322/canjclin.55.1.31).

19. Kareem FA, Nazar AS. Assessment of students' knowledge regarding breast self examination in Erbil City-Iraq. Iraqi Sci J Nurs. 2011; 24(1):69-72.

20. Amin TT, Al Mulhim AR, Al Meqihwi A. Breast cancer knowledge, risk factors and screening among adult Saudi women in a primary health care setting. Asian Pac J Cancer Prev. 2009; 10(1): 133-8.

21. Parsa $\mathrm{P}$, Kandiah $\mathrm{M}$, Mohd Zulkefli N, Abdul Rahman $\mathrm{H}$. Knowledge and behavior regarding breast cancer screening among female teachers in Selangor, Malaysia. Asian Pac J Cancer Prev. 2008; 9(1): 221-28.

22. Doshi D, Reddy BS, Kulkarni S, Karunakar P. Breast selfexamination: Knowledge, attitude, and practice among female dental students in Hyderabad City, India. Indian J Palliat Care. 2012; 18(1): 68-73. (doi: 10.4103/09731075.97476).

23. Facione N C, Giancarlo C, Chan L. Perceived risk and help seeking behavior for breast cancer. Cancer Nurs. 2000; 23(4): 256-64. (doi: 10.1097/00002820-20000800000002).

24. Nystrom L. How effective is screening for breast cancer? $\mathrm{Br}$ Med J. 2000; 321(7262): 647-9. (doi: 10.1136/bmj.321.7262.647). 
25. Petro-Nustus W, Mikhail PI. Factors associated with breast self-examination among Jordanian Women. Public Health Nurs. 2002; 19(4): 263-71. (doi: 10.1046/j.1525-1446.2002.19406.x).

26. Hadi MA, Hassali MA, Shafie AA, Awaisu A. Evaluation of breast cancer awareness among female university students in Malaysia. Pharm Pract. 2010; 8(1): 29-34. (doi: 10.4321/S1886-36552010000100003).

27. Chee H, Rashidah S, Shamsuddin Intan O. Factors related to the practice of Breast Self Examination (BSE) and pap smear screening among Malaysian women workers in selected electronics factories. BMC Womens Health. 2003; 3(1): 3. (doi: 10.1186/1472-6874-3-3).

28. Ali SAM. Knowledge and practices of females about breast cancer and breast self-examination in Al-Mansur Institute of Medical Technology /Baghdad/ Iraq. AlMustansiriya J Sci. 2012; 23(3): 11-20.

29. Abdel Hadi MS. Breast cancer awareness among health professionals. Ann Saudi Med. 2000; 20(2): 135-6. (doi: 10.5144/0256-4947.2000.135).

30. Montazeri A, Vahdaninia $M$, Harirchi I, Harirchi A $M$, Sajadian A, et al. Breast cancer in Iran: Need for greater women awareness of warning signs and effective screening methods. Asia Pac Fam Med. 2008; 7(1): 6-13. (doi: 10.1186/1447-056X-7-6).
31. Dündar P, Ozmen D, Ozturk B, Haspolat G, Akyildiz F, Coban $S$, et al. The knowledge and attitudes of breast self examination and mammography in a group of women in a rural area in Western Turkey. BMC Cancer. 2006; 24(6): 43-6. (doi: 10.1186/1471-2407-6-43).

32. Nafissi N, Saghafinia M, Motamedi MK, Akbari ME. A survey of breast cancer knowledge and attitude in Iranian Women. J Can Res Ther. 2012; 8(1): 46-9. (doi: 10.4103/0973-1482.95173).

33. Akhtari-Zavare $M$, Juni $M H$, Abdul Manaf $R$, Ismail I Z \& Said S M. Knowledge on breast cancer and practice of breast self examination among selected female university students in Malaysia. Med Health Sci J. 2011; 7(3): 49-56. (doi: 10.15208/mhsj.2011.132).

34. Abdullah AM, Ali RM. The impact of an education program upon women's knowledge in managing breast self-examination. Iraqi Sci J Nurs. 2010; 23: 42-55.

35. Abd El Aziz HM, Akl OA, Ibrahim HK. Impact of a health education intervention program about breast cancer among women in a semi-urban area in Alexandria, Egypt. J Egypt Public Health Assoc. 2009; 84(1\& 2): 219-43.

36. Tu SP, Reisch LM, Taplin SH, Kreuter W, Elmore JG. Breast self-examination: Self-reported frequency, quality and associated outcomes. J Cancer Educ. 2006; 21(3): 175-81. (doi: 10.1207/s15430154jce2103_18).

37. Janda $M$, Obermair A, Haidinger $G$, Waldhoer T, Vutuc $C$. Austrian women's attitudes toward and knowledge of breast self examination. J Cancer Educ. 2000; 15(2): 91-4. 